\title{
Critical thinking of young people in the context of digitalization of the educational process
}

\author{
Anastasiya Kovaleva* and Olga Volkonskaya \\ Don State Technical University, 344010, Rostov-on-Don, Russian Federation
}

\begin{abstract}
Recently, it has been customary in Russian society to talk about the crisis of all levels of education. Undoubtedly, one can argue for a long time about the crisis in such spheres of public life as the economy and politics, but perhaps the only comprehensive problem that affects the entire society as a whole is the crisis of education, which arose due to quite understandable reasons.

The development of any society, the its transformation and individual spheres of society inevitably make it necessary to form new social values, guidelines, incentives and motivations to achieve new outlined or already clearly formulated goals. Inextricably linked with this process, the formation of worldview attitudes has developed since childhood, and especially in adolescence, at that period of time when the first attempts are made to make independent decisions, to bear responsibility for them, to encounter restrictions and prohibitions. During this period, when goal-setting is formed in the mind of a young person, attitudes and priorities are formed, not just an important, but sometimes a decisive role begins to play the ability to critically analyze incoming information, which will form the basis of these processes.
\end{abstract}

\section{Introduction}

The greatest amount of information that somehow forms the basis for the formation of intelligence, knowledge, skills and various skills comes to a person in the process of learning at all levels of the educational process. Therefore, it is not surprising that the attention is paid to its regulation and optimization in any developed state. The realities of the modern world have clearly shown the inevitability of computerization and digitalization of education. This issue was particularly acute in Russia in the first half of 2020, during the introduction of forced restrictions related to the threat of the spread of a new coronavirus infection (COVID19), when for a relatively long period of time, absolutely the entire learning process was converted into online format.

If we talk about the process of digitalization of society and public relations, we need to understand that it represents a number of interrelated opportunities and limitations for participants in such social relations. In this regard, there are still a lot of questions about the impact of the process of digitalization and determining its impact on the culture of youth, including professional, political, and economic.

* Corresponding author: a.kovaleva-1@yandex.ru 
On the one hand, we can say that the degree of involvement of Russian youth in the Internet space and communications through the global network is comparable to the corresponding indicators of the leading countries in this matter, for example, such as the United States, Sweden, South Korea, etc. On the other hand, critical thinking, as a completely separate element, an individual competence that was singled out in the framework of the World Economic Forum as one of the competencies of the future, does not receive due attention and development in the context of the lack of digital educational environment, the lack of unified effective distance learning technologies and a sharp transition from the traditional process of acquiring knowledge to its remote counterpart.

All this allows us to propose a hypothesis, according to which the digitalization of the educational process without professional navigation not only does not contribute to a critical attitude to the received and perceived information, but also reduces the level of development of critical thinking.

\section{Materials and methods}

Our analysis of the peculiarities of the formation and application of critical thinking by young people of the components and content of the digital environment is based on the study of approaches to solving this issue by representatives of various scientific schools in Russia and abroad.

All the main approaches to the definition of this issue that exist today can be divided into two large groups. The first of them is the approach defined and outlined at the World Economic Forum, which implies focusing on two aspects:

1. The ability to reasonably question any new information received and perceived;

2. The skill and ability to transform the results of an analytical process into a technology for solving an existing problem.

Accordingly, within the framework of the World Economic Forum, critical thinking was proposed to be understood as the ability to skeptically evaluate arguments, assumptions, abstract concepts, data, in order to make a judgment and formulate appropriate proposals for solving problems. [1]

For example, regarding the definition of critical thinking through the ability of an individual to develop and apply ways to solve situational problems, R. Paul points out that "critical thinking is self-directed, self-disciplined, self-controlled and self-correcting thinking, which entails effective communication and problem-solving abilities". [2]

The second group can be attributed to the opinion of $\mathrm{D}$. Obstfeld, who together with his co-authors established the necessary signs of critical thinking in his approach:

1. the ability to find or create meaning (sense making);

2. skills of interpretation and comprehension of the revealed patterns. [3]

The third group may include approaches to critical thinking that focus on the direct content of the critical thinking process. For example, E. Glazer proposed to consider the ability to critical thinking as a set of three necessary elements:

1. thoughtful consideration of the problem and topic within the range of experiences;

2. knowledge of methods of logical analysis and reasoning;

3. skills in applying these methods. [4]

The following approach to understanding and defining critical thinking is expressed in the works of P. A. Facion [5]. This approach requires the existence of a certain set of necessary cognitive skills at the heart of critical thinking, which include: interpretation, analysis, evaluation, inference, explanation, and self-regulation.

The approach, which was formulated by V. R. Ruggiero, involves the definition of critical thinking through its methods, including:

1. disclosure of the intellectual context; 
2. awareness of the problem of the right way of thinking and development of a strategy to eliminate these problems. [6]

An important starting point for the theoretical analysis of the critical thinking of modern youth at the beginning of empirical research is the place that is given to critical thinking in the competence model of the XXI century. [7] The analyzed competence is among the innovative skills along with the problem-solving skills and the ability to be creative.

The most receptive to the acceptance and assimilation of new ideas is the youth environment, which is characterized by certain psychological characteristics, among which the most common are: emotional receptivity, youthful maximalism, the search for the meaning of life or vocation. These psychological characteristics of the individual are combined with categorical, straightforward, and somewhat unwavering decisions.

The specifics of the psychological characteristics of a young person's personality in combination with an unformed system of value-semantic orientations act as a kind of channel for receiving new raw information.

Young people's psychological characteristics - immaturity naivety and primitiveness of thinking - are often used and taken as a basis for the manipulation of their minds.

Theoretical and methodological uncertainty in the analysis of the phenomenon of critical thinking leads us to the need to explore both theoretical and practical attempts to interpret this phenomenon, and implicit ideas about critical thinking.

\section{Results}

Critical thinking is one of the types of intellectual activity of a person, which is characterized by a high level of perception, understanding, and objectivity of the approach to the information field surrounding him.

The Critical Thinking Development technology is developed by the International Reading Association of the University of Northern Iowa and Hobard and William Smith Colleges. The authors of the program are Charles Temple, Ginny Steele, and Kurt Meredith. [8] This technology is a system of strategies and methodological techniques designed for use in various subject areas, types and forms of work. It allows you to achieve such educational results as the ability to work with an increasing and constantly updated information flow in different fields of knowledge; the ability to express their thoughts (orally and in writing) clearly, confidently and correctly in relation to others; the ability to develop their own opinion based on the understanding of various experiences, ideas and ideas; the ability to solve problems; the ability to independently engage in their own training (academic mobility); the ability to cooperate and work in a group; the ability to build constructive relationships with other people [9]. This technology appeared in Russian education in 1997. It was developed with the support of the Consortium of Democratic Pedagogy and the International Readers' Association.

The modern educational system should not only provide the ability to adequately perceive information, but also teach how to receive it, operate with it, apply it to specific life situations, and interpret this information [10]. Thus, new knowledge is born on the basis of what is already available. It is also necessary to develop in the student a certain amount of skills and abilities to work with various sources of knowledge, to develop the ability not to reproduce knowledge, but to expand it, to apply it in various life situations. It is important to be able to form your own attitude to facts, problems, to be able to listen to others, to find joint ways to solve problems [11].

In 2016, Stanford University tested more than 7800 high school students and students on the ability to evaluate information from the Internet. The result came down to one word: "none." For example, the organizers of the experiment suggested that high school students try to assess the reliability of the information that was posted on one of the sites. The text 
about the appearance of double flowers in the vicinity of Fukushima was illustrated by a photo (see Fig. 1)

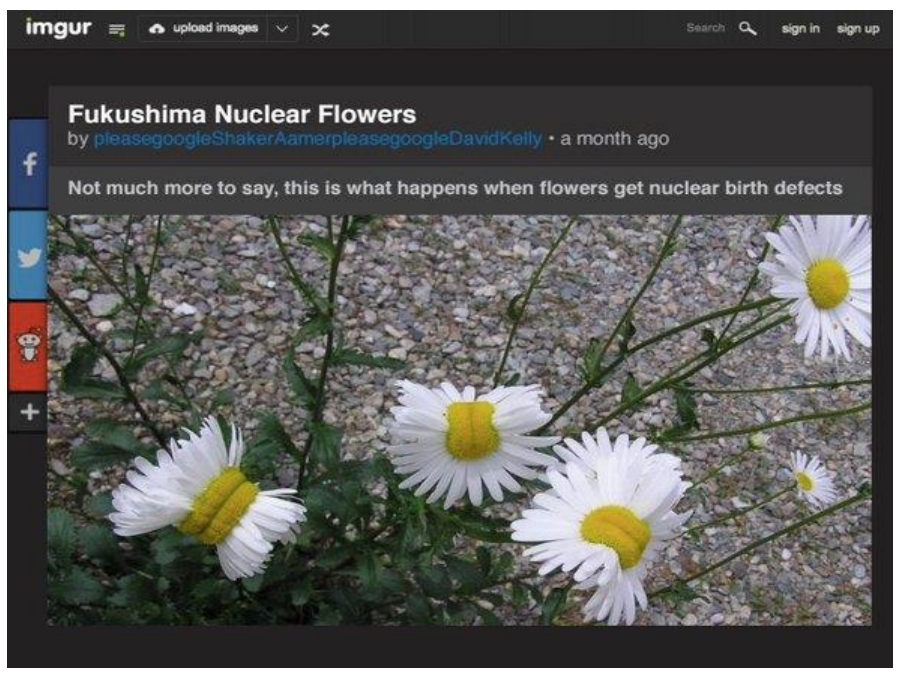

Fig. 1. A site where high school students were asked to evaluate the reliability of information as part of a Stanford University study.

The older age group - students were asked to assess the reliability of information on the social network Twitter, which indicated that two out of three owners of firearms are supporters of the already-established control over the circulation of weapons. The results of the study were really disappointing (see Fig. 2).

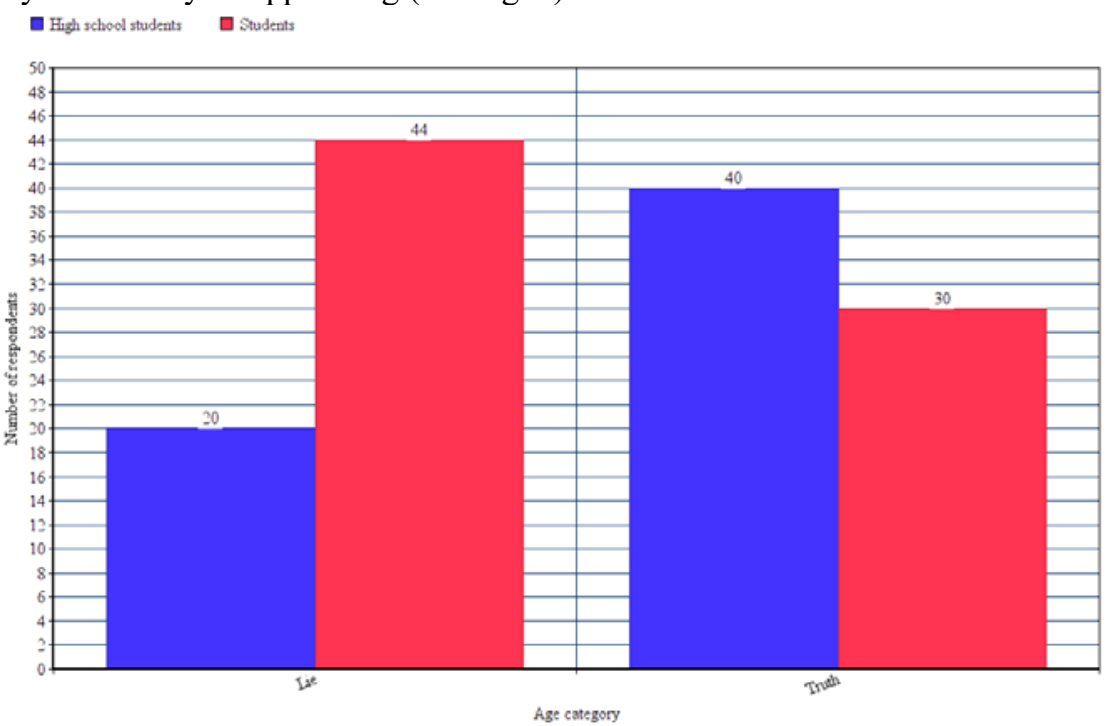

Fig. 2. The results of the study.

The students were not confused by the lack of a source of information and reliable evidence of the authenticity of the photo. $40 \%$ of 170 high school students considered that the very presence of a photo indicates the reliability of the news. Only $20 \%$ of you-said doubt in its veracity. And the fact that the results of the NRA survey could be influenced by the 
personal interest of the organization itself, which advocates for stricter regulation of gun trafficking, was indicated by only $44 \%$ of students.

Perhaps, today the situation has not changed dramatically, but the perception of the flow of information from the global network and the need to process and use it have become almost the only possibility of effective existence in the modern world. On this occasion, psychologist Diane Halpern almost 20 years ago expressed the idea in an article that is still quite relevant: "People now have an incredible wealth of information at their fingertips thanks to the Internet and other services in just a few minutes of searching on a computer. The problem is knowing what to do with this data stream. Information must be selected, interpreted, digested, evaluated, studied, and applied, or it becomes no more useful on a computer screen than on a library shelf."

\section{Discussion}

The ability to question incoming information helps to avoid falling into the trap of groupthink [12]. It occurs when people want to agree with each other very much. This is quite common phenomenon, because we are all social beings. Being part of a cohesive group gives us a pleasant feeling of warmth.

In the 1950s, the psychiatrist Solomon Asch demonstrated groupthink in a series of experiments. For the experiment, he gathered eight people in a room. Seven of them were fake and only one was a real test subject. Asch lined up the group in a row and asked each of them to say which of the lines was the longest. Seven fake participants deliberately gave the wrong answers. The real subject stood last. About 30\% of the volunteers agreed with the fake people and gave answers that did not seem right at first glance.

This reaction begins at the physiological level with one of the "happiness hormones" oxytocin. It promotes the emergence of a strong relationship, for example, in the company of friends or a sports team, encourages people to trust each other, empathize, share and help. But oxytocin also has a dark side, namely, it is responsible for forming distrust of those outside the group. And in some cases, it causes jealousy, pleasure from the misfortunes of another and aggression. Once inside the group, the person does not want to fall out of it. And if the payment for the love of others is a rejection of one's opinion, the majority willingly agrees with it.

A similar situation is occurring in online settings, although we cannot fully talk about the establishment of such a team relationship. However, the views expressed and repeated would inevitably gather supporters from among those who could not espouse this view.

The situation is similar in the perception of information from a certain "authority", whether it is a person who, in the mind of a young person, has certain advantages and earns trust, or entire resources, and information platforms, the information on which it is customary to trust. So, for example, the information available on such a resource as Wikipedia is only rarely questioned and is perceived as true without proper critical attitude to it. Teenagers do not verify the information obtained from this source, which becomes clear when preparing the report.

\section{Conclusion}

The work of the teaching staff in the use of technology for the development of critical thinking is important. This technology involves the structure and content of classes, which includes three phases: challenge, comprehension and reflection. The ability to form creative and critical thinking and teach these types of students determines the level of professional competence of the teacher [13]. How the teacher will manage to train students critically to 
think, provide perception, storing, understanding, judgment and other thought processes depends efficiency of activity of students, and, therefore, and efficiency of the process of training.

Critical thinking is a necessary component of the professional competence of not only the teacher, who also directs students in the direction of rational thinking, but also parents, who often completely restrict the freedom of the child [14]. Since critical thinking is social, it is most often manifested in various discussions, disputes, reasoning of teachers and students. In such cases, students are equal participants in what is happening, and perceive the learning process not just as a jagging scientific program, but as an exchange of experience between students and the teacher. The relationship between the teacher and the students "frees the teacher from the role of omniscience, but forces him to accept the equally difficult role of the organizer of the process of knowledge."

Talking about the development and formation of critical thinking of young people means talking about the development of their goal-setting for improving the quality of rational thinking, improving certain thinking skills and abilities, and being ready to use them in practice, whether it is study or work [15]. B.M. Teplov believed that criticality is the ability to strictly evaluate the work of thought, carefully weigh all arguments for and against emerging hypotheses and subject these hypotheses to comprehensive testing. The ability to analyze and make choices is an integral part of a developed person, without which she will be forced to rely on the opinion of authorities and experts all the time. Therefore, the first condition for the comprehensive development of the personality is the presence of critical thinking.

Perhaps the absence of independent thought is due to the fact that the younger generation has no ideals. Russian youth experience certain difficulties of social self-development, and do not have guidelines for the movement. There is a crisis of culture, where old norms and values no longer work, and new ones do not yet exist.

\section{References}

1. New Vision for Education Unlocking the Potential of Technology (World economic forum), http://www3.weforum.org/docs/WEFUSA_NewVisionforEducation_Report2015.pdf, last accessed 2021/03/05.

2. R. Paul, L. Elder, The Miniature Guide to Critical Thinking Concepts and Tools (Foundation for Critical Thinking Press, 2008).

3. K. Weick, K.M. Sutcliffe, \& D. Obstfeld, Organization Science 16(4), 409-421 (2005).

4. Edward M. Glaser, An Experiment in the Development of Critical Thinking (Bureau of Publications, Teachers College, Columbia University, New York, 1941).

5. Dr. Peter A. Facione, Critical Thinking: A Statement of Expert Consensus for Purposes of Educational Assessment and Instruction (APA Delphi Principal Investigator, Fullerton, 1989).

6. V.R. Ruggero, On the other side of emotions and feelings: a guide to critical thinking (Flint: Nauka, Moscow, 2006).

7. Curriculum and Instruction: A 21st Century Skills Implementation Guide, https://ru.scribd.com/document/349799910/p21-stateimp-curriculuminstruction-pdf, last accessed 2021/03/07.

8. Emily R. Lai, Critical Thinking, A Literature Review, https://images.pearsonassessments.com/images/tmrs/CriticalThinkingReviewFINAL.p df, last accessed 2021/02/04. 
9. Daniel T. Willingham, How to Teach Critical Thinking, https://uploadsssl.webflow.com/5b69a01ba2e409501de055d1/5e6a52f1240e17ae82e7af7c How-toteach-critical-thinking-Willingham.pdf, last accessed 2021/03/01.

10. Shazaitul Azreen Rodzalana, Maisarah Mohamed Saat, The Perception of Critical Thinking and Problem Solving Skill among Malaysian Undergraduate Students, https://core.ac.uk/download/pdf/162031508.pdf, last accessed 2021/02/017.

11. SlaLana ŽivkoviL, A Model of Critical Thinking as an Important Attribute for Success in the 21st Century, https://www.researchgate.net/publication/309348466_A_Model_of_Critical_Thinking as_an_Important_Attribute_for_Success_in_the_21st_Century, ${ }_{-}^{-}$last ${ }^{-}$accessed $20 \overline{2} 1 / 02 / 17$.

12. Jonathan Heard, Claire Scoular, Daniel Duckworth, Dara Ramalingam and Ian Teo, Critical Thinking: Skill Development Framework, https://core.ac.uk/download/pdf/287816564.pdf, last accessed 2021/02/17.

13. Margaret M. Lloyd and Nan Bahr, Thinking Critically about Critical Thinking in Higher Education, https://www.researchgate.net/publication/228513767_Thinking_Critically_about_Criti cal_Thinking_in_Higher_Education, last accessed 2021/01/25.

14. Ken Changwong, Aukkapong Sukkamart and Boonchan Sisan, Journal of International Studies 11(2), (2018).

15. Linda M. Murawski, Critical Thinking in the Classroom...and Beyond, https://files.eric.ed.gov/fulltext/EJ1143316.pdf, last accessed 2021/02/28. 